\title{
A INTERPELAÇÃO IDEOLÓGICA NO DISCURSO PUBLICITÁRIO: OS USOS DO CORPO E DAS LINGUAGENS NÃO-VERBAIS PELA MÍDIA NA MODERNIDADE
}

\section{IDEOLOGICAL INTERPELATION IN ADVERTISING DISCOURSE: THE USES OF THE BODY AND NON-VERBAL LANGUAGES BY THE MEDIA IN MODERNITY}

\author{
Leda Verdiani Tfouni \\ Arthur Egydio de Sousa Santos
}

RESUMO: Pretende-se refletir sobre o funcionamento do discurso em propagandas, buscando entender como o não-verbal consegue significar, em contato com a História e a ideologia. O corpus é constituído por anúncios de anéis que enfatizam características estéticas do corpo humano. A análise apontou que a opção pelo não-verbal decorre de uma não implicação do autor da peça com o sentido. Isto parece reforçado pela escolha de imagens que buscam direcionar a interpretação para o cômico, cuja característica é a flexibilização dos interditos, possibilitando que sejam postos em jogo sentidos censurados.

PALAVRAS-CHAVE: discurso, linguagem não-verbal, publicidade, mídia.

ABSTRACT: We intend to investigate how non-verbal discourse functions in propaganda pieces, in an attempt to understand the ways that this kind of discourse succeeds in producing meanings in contact with history as well as ideology. The corpus is made up of advertisements of rings which emphasize characteristics of the human body. The analysis shows that the option for non-verbal language is a consequence of an absence of implication with the expressed senses. This seems to be reinforced by the choice of images that seek to direct the interpretation towards the comic, whose main characteristic is the flexibilization of the prohibited, making it possible that the socially forbidden senses circulate.

KEYWORDS: discourse, non-verbal language, propaganda, media.

* Universidade de São Paulo - USP, Ribeirão Preto, Professora Titular. lvtfouni@usp.br

** Universidade de São Paulo - USP, Ribeirão Preto, Psicólogo. artutuga@ yahoo.com.br 



\section{INTRODUÇÃO}

A mídia tem papel importantíssimo no assujeitamento ideológico da grande massa, que "descobre" por esse meio quais são suas "verdadeiras" necessidades, e qual seu preço. Torna-se essencial buscar compreender de que maneira as diferentes linguagens vêm sendo usadas na criação dessas necessidades.

No presente trabalho, buscou-se atuar em uma região de intersecção de algumas temáticas articuladas através dos conhecimentos advindos da Análise do Discurso (AD) pêcheutiana (1988, 1969, 1990, 1999), a saber, a publicidade, a sexualidade e o uso de linguagens não-verbais. $O$ contato inicial com o corpus se deu pela internet, através de um blog chamado Brain Storm (www.brainstorm9.com.br, acessado várias vezes durante o ano de 2006), onde são encontradas diversas peças e eventos publicitários bastante interessantes. $\mathrm{O}$ trabalho também se justifica pela tentativa de aplicação do conhecimento da Análise do Discurso ao âmbito de linguagens não estritamente textuais, já que pouco se pode encontrar a este respeito na literatura corrente. Como se pode perceber ao entrar em contato com o corpus, à primeira vista, estas peças são quase totalmente não-verbais, uma vez que fazem uso de uma linguagem basicamente fotográfica para anunciar seu produto. Até mesmo a escolha dos tamanhos - pequenos - das partes escritas, em detrimento das fotos grandes, parece, inicialmente, apontar para um deslocamento do eixo da verbalização para segundo plano. 
A partir deste quadro geral do corpus, torna-se clara a necessidade de abordagem de alguns pontos, essenciais para que se conheçam as condições de produção desses discursos. Estes pontos são: o uso da linguagem nãoverbal em anúncio publicitário; o uso do corpo e da temática da sexualidade e do poder como artifício de persuasão à compra; e, por fim, o uso do cômico, ou melhor, do chiste, como artifício discursivo.

Em primeiro lugar, quando são abordados quaisquer tipos de práticas discursivas, torna-se essencial que seja considerada a existência de múltiplas e diferentes linguagens. Toda e qualquer ação transformadora - trabalho simbólico -, realizada pelo homem em certo momento sóciohistórico, é carregada de sentidos, ou seja, significa. As diversas formas assumidas por cada prática discursiva, por cada trabalho realizado na História, constituem as múltiplas linguagens, podendo estas variar do mais formal dos textos escritos à mais vanguardista das expressões musicais, por exemplo. Estabelece-se aí uma importante diferenciação, presente na literatura pertinente, entre linguagem verbal e linguagem não-verbal. A própria nomenclatura utilizada (verbal e não-verbal) oferece uma prévia do tratamento recebido por cada um destes "tipos" de linguagem na sociedade contemporânea, já que uma, a segunda, é definida em função da outra, a primeira, de nomenclatura "verbal".

Acredita-se, assim como fazem Orlandi (1995), Aguiar (2004) e Souza (1997), que a existência de formas diversas de linguagem, constituídas por diversas matérias significantes, deve ser entendida como uma necessidade histórica, haja vista que certos sentidos só são passíveis de aparição e atualização através de certas materialidades específicas, que são partes essenciais das condições de produção do discurso. No trabalho com análise do discurso não-verbal, é essencial que se tenha em mente que a maneira como cada prática discursiva produz sentidos não é alheia à sua materialidade, mas, sim, dependente desta. "É na prática material significante que os sentidos se atualizam, ganham corpo, significando particularmente" (ORLANDI, 1995: 1). Quando são ignoradas estas particularidades, de cada uma das linguagens, é apagada uma grande distância entre elas. Acontece, então, o que Orlandi (1995) denomina sobredeterminação do não-verbal pelo verbal; reduzem-se as manifestações discursivas não-verbais àquelas de natureza verbal.

A significação deve ser considerada frente à sua matéria significante específica, sendo impossível realizar leituras verbais de práticas discursivas não-verbais sem que haja alterações importantes nos sentidos em questão. "A 
palavra fala da imagem, a descreve e traduz, mas jamais revela a sua matéria visual" (SOUZA, 1997: 2). Não obstante, a tradução verbal a que se refere Souza não pode ser considerada neutra ou inofensiva, uma vez que, como a própria autora diz, não consegue reproduzir o choque do interlocutor com a materialidade significante não-verbal, o que impossibilita a aparição do sentido original. Como aponta Orlandi (1995), sob certas condições, é possível que se realizem intercâmbios de sentidos entre as linguagens, a que Pêcheux (1988) chama de produção de paráfrases, o que não implica, de forma alguma, dizer que o sentido permaneça o mesmo.

Souza (1997), contudo, aponta para uma importante faceta deste processo de parafraseamento de, por exemplo, imagens, cujo uso é bastante comum em nossa mídia contemporânea, notadamente a jornalística. Refere-se a uma tentativa de condução da interpretação, através do oferecimento de uma "leitura" supostamente esclarecedora do que é apresentado, seja música, imagem etc. São, como colocado por Pêcheux (1990), "procedimentos para se administrar a interpretação", cuja eficácia, todavia, deve ser discutida.

Souza (1997: 4) afirma que, assim, "as imagens são apagadas por um processo de verbalização, de paráfrase, porque reproduzem um determinado enfoque", o que ocasiona um processo de imposição interpretativa, segundo a ideologia do locutor televisivo, que tira do telespectador sua autonomia enquanto sujeito do discurso. Como exemplo, cita os programas humorísticos, onde gravações de risadas ou a voz em off do apresentador "definem" a cena, por mais absurda ou humilhante que seja, como engraçadas, levando o espectador a compartilhar deste sentido.

Contudo, no presente trabalho, acredita-se que tais afirmações devem ser feitas com cautela, uma vez que, por mais que se tente controlá-la, a deriva está sempre presente, já que os indivíduos são interpelados em sujeitos inconscientemente por formações ideológicas bastante distintas, o que garante uma ampla possibilidade de sentidos para a mesma prática discursiva. Não acreditamos que as imagens sejam apagadas pela "leitura" que lhes é imposta. Muito pelo contrário. Acreditamos que a matéria significante desta prática discursiva muda, nada mais. Contudo, continua sujeita à heterogeneidade da ideologia. Há uma mudança na matéria significante, mas ela não deixa de ser não-verbal. Passa a ser uma mescla entre verbal e não-verbal, e, em seu todo, como uma Gestalt, no choque com o interlocutor, passa a produzir novos sentidos. Trata-se se uma combinação de duas ou mais linguagens, sem que uma tenha que se sobressair. 
Neste ponto, torna-se importante o questionamento acerca da simultaneidade de linguagens em certas práticas discursivas. $\mathrm{O}$ caso de uma música em que se conta uma história através da sua letra, por exemplo, parece se aproximar bastante do exemplo apresentado por Souza (1997), já que contém a interação de duas ou mais linguagens, neste caso a linguagem musical e a poética, para formar um todo, maior que cada uma destas linguagens isoladas, e significado de maneira particular. A letra ou a melodia de uma música, isoladas, não produzem os mesmos sentidos que a música inteira, pois se tratam de condições de produção distintas. Além disso, existe uma faceta não-verbal da própria voz humana: as suprassegmentais.

Torna-se claro, então, que não deve haver uma separação entre a análise do discurso verbal e a análise do discurso não-verbal e, sim, que estas duas devem andar juntas e complementar-se, porque, no mundo, verbal e não-verbal interagem, se complementam. Assim como não é possível a separação de forma e conteúdo, parece pertinente que não se tente separar linguagens distintas que interagem na formação de um sentido total. $O$ sentido provocado por uma destas linguagens separada da outra seria, certamente, distinto, podendo ser considerado parcial.

Com isso em vista, torna-se relevante a utilização da Análise do Discurso na busca de um dispositivo analítico capaz de dar conta de um corpus não-verbal ou misto. Maingueneau (1984) já afirmava esta possibilidade, propondo abandonar a órbita da estrita textualidade, representada por textos verbais, para abordar outras manifestações discursivas, como o cinema ou a pintura, por exemplo. Acredita-se que os principais conceitos da $\mathrm{AD}$, tais como as condições de produção, o interdiscurso, as formações discursivas e ideológicas, os esquecimentos número 1 e 2 , a metáfora, a metonímia, a ideologia etc., são aplicáveis à linguagem não-verbal. É importante, contudo, que se entenda o discurso como uma prática discursiva, como "um trabalho (no caso, simbólico) entre o homem e sua realidade natural e social. Prática significante, pois, ação transformadora" (ORLANDI, 1995: 14). Esta noção de prática permite que se trabalhe o discurso sem o efeito de dominância da linguagem verbal, uma vez que abandona a noção de discurso como sequência de frases, textos etc. Discorreremos mais a respeito desta posição a seguir.

\section{A ANÁLISE DO DISCURSO}

$\mathrm{Na}$ busca pela reflexão acerca das formas de interpretação e dos mecanismos subjacentes a elas, a Análise do Discurso se vale de um 
dispositivo teórico que busca elucidar a produção de sentidos, no contato do sujeito com a linguagem e com a História. A seguir, serão apresentados alguns dos principais conceitos constituintes deste dispositivo teórico, essenciais para a compreensão do discurso enquanto trabalho simbólico.

Dentro desse referencial, discurso é definido como efeito de sentidos entre interlocutores, produzido sobre uma materialidade significante específica. Um dos pontos iniciais para se pensar qualquer prática discursiva diz respeito ao conhecimento de suas condições de produção, que abrangem, basicamente, o contexto imediato de enunciação, abarcando os sujeitos envolvidos, a matéria significante específica de cada prática, o lugar onde este discurso aparece, enfim, todas as variáveis referentes à situação atual concreta de aparição do discurso, e ainda o contexto sóciohistórico, ideológico, que abrange uma esfera social mais ampla, como as formas de organização da sociedade em questão, as relações de poder e hierarquia, entre outras.

Outro conceito relevante é o de interdiscurso, ou "já-lá", que se refere a todos os dizeres e sentidos existentes e esquecidos acerca de determinado assunto. Trata-se de tudo que já foi dito e significado e que, mesmo esquecido, significa até hoje. Como ressalta Orlandi (1999), o fato de esta memória discursiva estar esquecida é a própria condição de existência para o dizer atual, haja vista que todo discurso é retomado de algum outro, que o sustenta e o torna dizível, realizável. Todo discurso se inscreve na memória discursiva, onde tem sua origem e onde se filia a certos dizeres e não outros, devido à sua relação com a ideologia. $\mathrm{O}$ interdiscurso, ou memória discursiva, é formado através da significação do real da História, que produz acontecimentos aos quais são atribuídos sentidos, que, esquecidos e "armazenados" no "já-dito", servirão de fundamentação para novos sentidos, e assim por diante. O interdiscurso possibilita a tensão entre paráfrase e polissemia, em que se assentam as práticas de linguagem. Os movimentos parafrásticos de linguagem dizem respeito ao retorno a regiões de dizer já existentes, à repetição de sentidos disponíveis, à reprodução de certas partes do "já-dito", mesmo que para isso busquem-se outras formas de dizer a mesma coisa. São produzidas "diferentes formulações do mesmo dizer sedimentado" (ORLANDI, 1999: 36). Já a polissemia é responsável pelos deslocamentos, derivas e rupturas nos processos de significação. Ela é responsável pela novidade, pelo movimento da interpretação. Apoiada no equívoco, a polissemia garante que os sentidos possam sempre vir a ser outros, impossibilitando uma estabilidade simbólica. 
Pêcheux (1988) enuncia a existência de dois esquecimentos presentes no discurso, os quais são considerados estruturantes, pois são necessários para a constituição dos sujeitos e dos sentidos, já que garantem a identificação destes sujeitos com o que é dito. O esquecimento número um, segundo Tfouni (1988), é responsável pelo ocultamento ideológico, determinado historicamente. Trata-se de um esquecimento da instância do inconsciente que "resulta do modo pelo qual somos afetados pela ideologia" (ORLANDI, 1999: 35). Neste esquecimento, o sujeito tem a ilusão de ser a origem do que diz, quando, na verdade, ele está sempre retomando algo já dito e já esquecido. Os sentidos apenas "aparentam" ter a origem no sujeito, mas são, de fato, determinados pela maneira como cada um se insere na História e na Linguagem. Como salientam Tfouni e Laureano (2004), algo "fala" à revelia do sujeito, os sentidos surgem independentemente de sua vontade. Quanto ao esquecimento número dois, que é da ordem da enunciação, ele se relaciona à ilusão, por parte do enunciador, da literalidade de seu dizer. O sujeito acredita que aquilo que diz é idêntico ao que pensa, Este esquecimento enunciativo, responsável pela ilusão referencial, é parcial e tem natureza semi-inconsciente, sendo possível ao sujeito ter acesso ao que é esquecido. Seu efeito se deve à criação, ao nível do pensamento e concomitante ao dizer, de uma série de cadeias parafrásticas do dito. Contudo, é importante relembrar que o modo particular de se dizer algo não é neutro para a significação. Mudando-se a materialidade específica significante, produz-se uma diferença importante nas condições de produção, possibilitando a deriva dos sentidos.

Outros conceitos-chave para a Análise do Discurso são os de ideologia e de sujeito. A ideologia, tomada como representação pelo indivíduo de suas condições materiais de existência, é responsável pelos efeitos de evidência. Atua através dos movimentos de interpretação que são por ela modulados e direcionados, porém, em seu funcionamento, através das ilusões de evidências, nega este movimento interpretativo, provocando a crença de que sentidos e sujeitos estão já sempre lá, possuindo uma correlação direta com o mundo. A ideologia provoca a naturalização do que é resultado do choque entre o simbólico e a História. Pode-se dizer, então, que o principal trabalho de ideologia consiste em produzir evidências, gerando no sujeito a ilusão de transparência e univocidade dos sentidos. Desta forma apagase todo o processo histórico de produção dos sentidos, através de filiações a certas formações discursivas, e não outras, que por sua vez se remetem a certas formações ideológicas. Apaga-se a relação do simbólico com a História e com a memória discursiva, ou interdiscurso. 
Já a evidência do sujeito proporciona a ilusão ao indivíduo de que ele é sempre sujeito; apaga o fato de que ele é interpelado pela ideologia em sujeito. Conduz (segundo Pêcheux, 1988) o indivíduo a acreditar que se coloca na posição discursiva que ocupa por sua própria vontade, dando-lhe a ilusão, tão cara ao ser humano, de liberdade de escolha, de autonomia. Esta interpelação do indivíduo em sujeito do discurso se efetua pela identificação (do sujeito) com a formação discursiva que o domina (isto é, na qual ele é constituído como sujeito): essa identificação, fundadora de unidade (imaginária) do sujeito apoia-se no fato de que elementos do interdiscurso (sob a dupla forma, enquanto 'pré-construído' e processo de 'sustentação' que constituem, no discurso do sujeito, traços daquilo que o determina) são reinscritos no discurso do próprio sujeito (PÊCHEUX, 1988). Como já dito anteriormente, para que façam sentido as práticas de linguagem devem se inscrever na História. $O$ resultado desta inscrição é o surgimento de possibilidades de sentidos e de dizeres, os quais se denominam discursividade. É o assujeitamento ideológico que determina a discursividade a que o sujeito terá acesso.

O sentido é assim determinado pela relação entre a linguagem em geral, o sujeito e a História. Logo, deve-se assumir que os gestos interpretativos não são totalmente livres, apesar de estarem longe de serem estanques. Podese afirmar, então, que a interpretação é necessariamente regulada em suas possibilidades, haja vista que existe uma discursividade, determinada pelas afiliações ideológicas e por sua relação com as memórias, institucionalizada e discursiva.

No que tange ao conceito de sujeito do discurso, é importante ressaltar que este é considerado intercambiável, ou seja, ele é entendido como uma posição discursiva entre outras, podendo ser mais ou menos efêmera. Não se leva em conta a posição empírica que ocupa o indivíduo, e sim a posição que ele ocupa ao produzir discursos, ao interpretar. Muitas vezes, o sujeito se posiciona em locais discursivos bastante distintos de sua posição empírica. A diferença entre posição discursiva e lugar empírico, sociológico, ocupado pelo sujeito, torna-se mais clara quando é levado em conta o conceito de formação imaginária, que representa a imagem, resultante de projeções, que se tem acerca da posição ocupada por cada sujeito. Como já afirmamos, nada significa por si só, ou seja, não existe sentido original ou natural. Os sentidos resultam de uma complexa relação entre a História, o simbólico e a ideologia. Pode-se dizer que as filiações, em termos de formações ideológicas, delimitam certas regiões de sentidos 
do interdiscurso, determinando aquilo que pode e deve der dito. A estas regiões de sentidos dá-se o nome de formações discursivas (ORLANDI, 1999). Os sentidos suscitados, então, dependem diretamente das formações discursivas dominantes às quais está filiado o sujeito. É destas posições discursivas que são "extraídos" os diferentes sentidos. Em síntese, "as palavras não têm sentido nelas mesmas, elas derivam seus sentidos das formações discursivas em que se inscrevem. As formações discursivas, por sua vez, representam no discurso as formações ideológicas" (ORLANDI, 1999: 43). A interpretação, então, é determinada ideologicamente, pois se dá através da inscrição do sujeito em uma formação discursiva.

\section{DISCURSO E INTERPRETAÇÃO}

Tendo em vista esta breve exposição acerca do arcabouço teórico da $\mathrm{AD}$, torna-se importante uma reflexão referente ao modelo epistemológico em que esta se assenta.

Em primeiro lugar, é essencial relembrar que a $\mathrm{AD}$ coloca a interpretação em questão. Admitindo a opacidade do significante, busca entender de que modo se dão os processos interpretativos para diferentes sujeitos. Neste sentido, busca-se não a interpretação de uma peça discursiva qualquer, mas sim a compreensão de seus modos de funcionamento, a forma como esta "atinge", ou afeta, os sujeitos, como se produz etc. Supõe-se, então, para que sejam cumpridos os requisitos metodológicos, que o analista esteja apto a se "afastar" da situação discursiva, a fim de controlar os efeitos de suas próprias filiações discursivas e ideológicas. Como exposto por Tfouni, contudo, o analista é incapaz de anular os efeitos de seu próprio assujeitamento, logo, deve-se estar claro que "as pré-disposições do investigador(a), seus pré-julgamentos, também fazem parte das condições de produção do conhecimento" (TFOUNI, 1992: 52).

Como exposto por Orlandi (1999), o analista, enquanto sujeito do discurso, tem importante função metodológica, já que ele é responsável pelo formato assumido por seu dispositivo analítico. Segundo a autora, mantêmse constantes, em qualquer análise, os conceitos teóricos da disciplina, o que ela denomina dispositivo teórico. Por sua vez, o dispositivo analítico, que engloba diversos elementos - entre eles, a natureza do corpus analisado, a questão que se busca trabalhar, as interfaces teóricas feitas -, depende diretamente da posição discursiva do pesquisador. Trata-se de como este "olha" para o material analisado. A particularidade dos dispositivos analíticos garante uma diversidade incontável de análises possíveis do mesmo corpus. 
O analista do discurso, então, deve estar apto a perceber estes indícios, que poderão levá-lo a compreender as formas de funcionamento do discurso. É possível, desta maneira, que o pesquisador consiga ter acesso a diversas regiões de sentidos distintas daquelas a que ele se afilia, enquanto sujeito do discurso. Utilizando-se dos indícios que a peça discursiva lhe fornece, o analista torna-se apto a compreender os diferentes sentidos em jogo, para diversos interlocutores, evitando se prender àqueles que lhe são imediatos, "transparentes", devido ao efeito ideológico elementar.

Essas são algumas considerações básicas acerca da opção teóricometodológica adotada neste trabalho.

As cores, timbres, texturas, luzes etc. têm sua historicidade, se referem a um interdiscurso para significar. O seguinte trecho, extraído de um fórum de discussão na internet, parece ilustrar bem este ponto:

Por exemplo, vê se tocando um B7(5\#), [você] não lembra de cara aquele som que toca em filmes ou novela em momentos de surpresa e/ou susto, tipo “Agnaldo, você aqui!?!?” Traaaam!!!! (sic). ${ }^{1}$

Como se pode perceber neste exemplo, a materialidade específica da linguagem musical - assim como todas as outras - se remete a um "jálä" já estabelecido, porém em movimento, para ser significar. Todos os usos já existentes, significados e esquecidos, deste acorde atuam, de forma inicialmente inconsciente, na produção do sentido. No momento do contato com o interlocutor, o acorde é capaz de provocar, como citado no exemplo, a sensação de surpresa, de susto... Estas sensações são percebidas como inerentes ao acorde, como se ele carregasse grudado a si estes sentidos, que são entendidos como naturais e únicos. Crê-se que as características físicas do acorde provocam susto ou surpresa e que, valendo-se disso, os produtores de filmes e novelas o usam para gerar certo "clima" desejado. Opondo-se a esta visão, a $\mathrm{AD}$ acredita que o caminho é justamente o oposto, ou seja, os usos do acorde ao longo da História formam uma memória discursiva, em que as práticas discursivas atuais buscam seus sentidos. A crença nesta "surpresa inerente ao acorde B7(5\#)" se deve à ilusão de evidência, devida ao efeito ideológico elementar. É pouquíssimo provável, por exemplo, que

\footnotetext{
${ }^{1}$ http://www.cifras.com.br/forum1/viewtopic.php?p=84693\&sid=5a2fe43be1752af5ea9b45 be864ac012. Acessado várias vezes durante 2006.
} 
Beethoven associasse estes mesmos efeitos de sentido ao acorde, uma vez que estaria sujeito a formações discursivas bastante distintas às do criador do exemplo acima.

Parece pertinente também que se considere que diferentes escolas, como o cubismo e o expressionismo, estão filiadas a distintas formações discursivas, o que implica formas próprias e divergentes de interpretar a pintura, por exemplo, e a forma como ela se atualiza em cada quadro histórico, em cada prática discursiva.

Souza (1997) afirma que quando interpretam imagens com o olhar o sujeito produz uma série de outras imagens - outros textos - devido ao caráter de incompletude inerente a qualquer tipo de linguagem. Ela afirma que acontece aí um processo de recorte de alguns dos elementos constitutivos da imagem, produzindo-se outra(s), sucessiva e infinitamente. Da mesma forma, um leitor faz recortes no texto lido.

Parece que há pouco a se contestar em tal afirmação, com exceção do caráter sucessivo e infinito dos recortes, uma vez que, como aponta Pantoni (2002), os sentidos advindos da interpretação vêm em forma de evidências, sendo isso parte do efeito ideológico elementar, também responsável pela falsa noção de transparência da linguagem. Logo, é pouco provável que os recortes realizados por um sujeito do discurso sejam infinitos, uma vez que ele tende a se prender em um sentido evidente, que o atinge como se fosse natural. A cada indivíduo cabe certa discursividade, delimitada pelas formações discursivas às quais está filiado. A interpretação não é aleatória, nem, tão pouco, livre. É inquestionável, porém, que infinitas, ou pelo menos incontáveis, são as possibilidades de interpretação e recortes de uma mesma peça discursiva. Como afirma Orlandi (1999), o interdiscurso aciona, faz valer, as condições de produção, gerando, assim, um recorte.

Quanto às condições de produção, torna-se especialmente importante que se atente para a observação cuidadosa da materialidade específica da prática discursiva. No caso do acorde $\mathrm{B} 7(5 \#)$, por exemplo, não basta que se conheça o acorde, mas também é necessário que se especifique o instrumento utilizado, o timbre escolhido, a intensidade do toque etc. Todas estas aparentemente pequenas variáveis são essenciais para a interpretação. Uma mesma sequência de notas tocadas levemente ao piano ou intensamente sopradas em uma gaita forma duas práticas discursivas diversas, produzindo sentidos também diversos. O timbre bastante característico da gaita provavelmente possibilitará sentidos de alguma forma ligados ao blues, enquanto o piano abrirá outro leque. Da mesma 
maneira, Pour Élise, interpretada por Ivo Pogorelich, por exemplo, não é a mesma prática discursiva que a famosa "musiquinha do gás".

Como dito anteriormente, o dispositivo de análise é aplicável ao nãoverbal contanto que se tenha o cuidado de não negligenciar a materialidade significante em questão. A crença contrária, segundo Orlandi (1995), tem suas raízes históricas. Segundo a autora, no percurso da reflexão acerca da linguagem, este fenômeno tem sua origem no momento em que o que é linguístico é equiparado à Linguística, ou seja, opera-se uma redução do fato de linguagem à disciplina que o estuda. Contígua a esta, outra redução ocorre, a saber: reduz-se o fato de significação à esfera do que é linguístico. Melhor dizendo, passa-se a creditar significação apenas aos fatos de linguagem definidos pela perspectiva da disciplina, a Linguística. Tem-se, então, o que a autora denomina "sobredeterminação do não-verbal pelo verbal".

Produz-se, então, como aponta Orlandi (1995) a "assepsia do não-verbal", devido à crença na verbalização necessária de toda e qualquer linguagem. Apaga-se, pelo verbal, a opacidade e a espessura de outras práticas. Segundo a autora, esta assepsia é consequência e causa de três mecanismos principais, a saber: o mito da informação, o prestígio do científico e o modo de relação do falante com a mídia.

O mito da informação se baseia na ilusão referencial, ou ilusão da literalidade, já citada anteriormente, que confere ao linguístico, ao verbal, um caráter de univocidade de sentido, de transparência, como se a significação de um texto, por exemplo, fosse única, estanque e anterior ao interlocutor. Sob este viés, denominado conteudístico, passa-se a pensar a linguagem como produção e transmissão de informação, supondo-se que um texto quer dizer " $\mathrm{x}$ " e somente " $\mathrm{x}$ ", para qualquer interlocutor, ignorando as possibilidades de atualização de sentidos, de deriva. A crença na literalidade do verbal é claramente exemplificada pela atuação da mídia, cuja finalidade é informar. Segundo Orlandi (1995: 10), "se a informação pode vir através de diferentes 'canais' (leia-se linguagens), e mesmo simultaneamente, no entanto, a sua formulação para consumo é verbal". Orlandi aponta o modo de relação do falante com a mídia como um importante mecanismo de manutenção da já citada "assepsia do não-verbal". Esta relação se encontra instrumentalizada pelo verbal. Dito de outra forma, o Homem, em sua necessidade constitutiva de produzir sentidos, de interpretar, imerso como está no discurso cotidiano, representado pelas palavras do senso-comum, presentes no dia-a-dia, fortemente determinadas pela mídia, sempre remete signos de naturezas distintas, que possuem formas de significar específicas, 
ao código verbal. Interpretam-se, então, linguagens variadas pelos mesmos procedimentos de significação verbal.

Torna-se importante ter em mente que a "assepsia do não-verbal" nada mais é do que um efeito ideológico, responsável pela crença de que é possível separar forma e conteúdo, quando, na verdade, como já dito anteriormente, a matéria significante é constitutiva do sentido produzido. Da relação do falante com a mídia, advém uma representação do verbal como uma espécie de "moeda de troca do sentido", ou seja, usa-se o linguístico como forma de cálculo do sentido, busca-se, grosso modo, o que certo sentido "quer dizer" em palavras, como se este processo fosse essencial. Neste processo, o verbal assume o lugar de neutro, de natural, universal. Como se fosse o centro, ao qual todas as outras linguagens devem se referir.

Existe a crença de que a linguagem verbal não é afetada pelas particularidades interpretativas do sujeito, ao contrário da linguagem nãoverbal, que seria considerada como muito mais suscetível a interpretações diversas, que esbarrassem na subjetividade. $O$ não-verbal parece representar o imprevisível. Logo, é possível que a "sobredeterminação do não-verbal pelo verbal" também se deva, em certo grau, à ideia de que o não-verbal é portador de um sentido selvagem, instável. A fim de se garantir uma interpretação supostamente estável, ou comum, interpreta-se tudo a partir do verbal, que é visto como transparente.

Como se sabe, contudo, é inadmissível para a $\mathrm{AD}$ supor a existência de uma transparência do discurso, seja ele verbal ou não. É importante salientar que todas as práticas discursivas estão sujeitas à interpretação, à atualização de sentidos; enfim, à deriva.

\section{ANÁLISE DO CORPUS}

Apresentamos a seguir o corpus que foi analisado. 

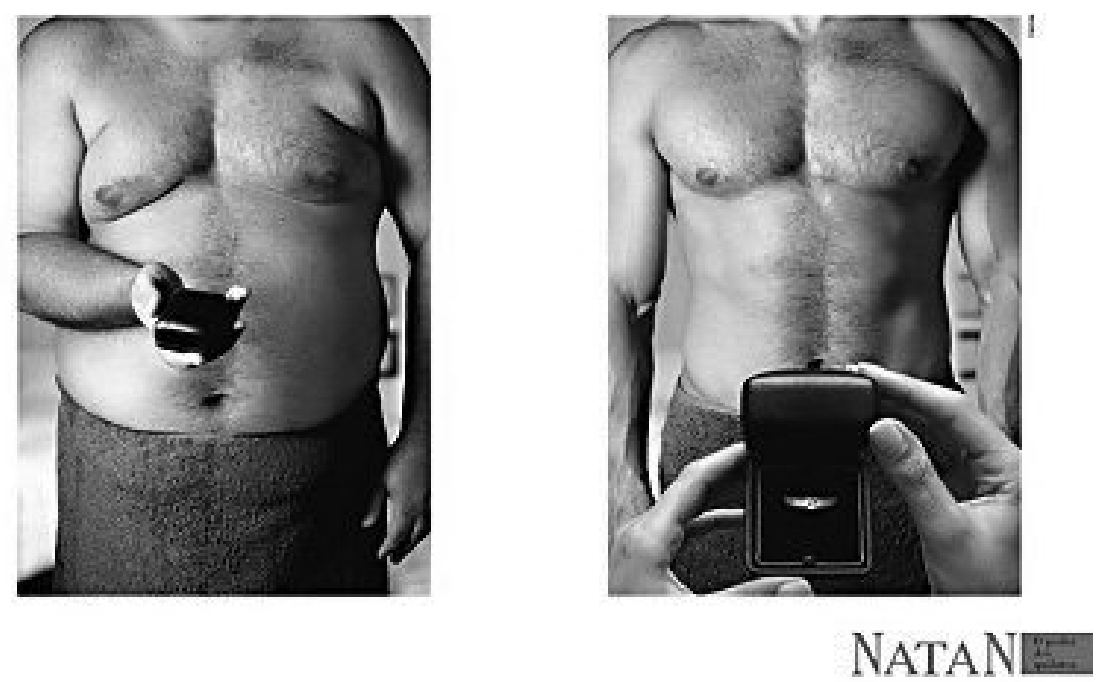

Peça 1
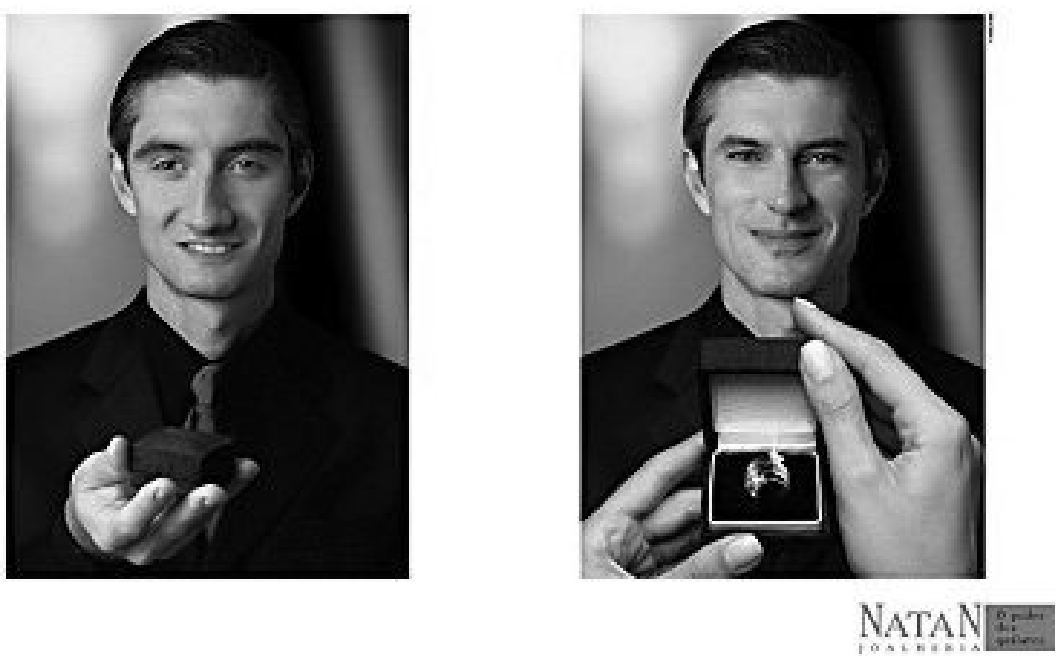

Peça 2 

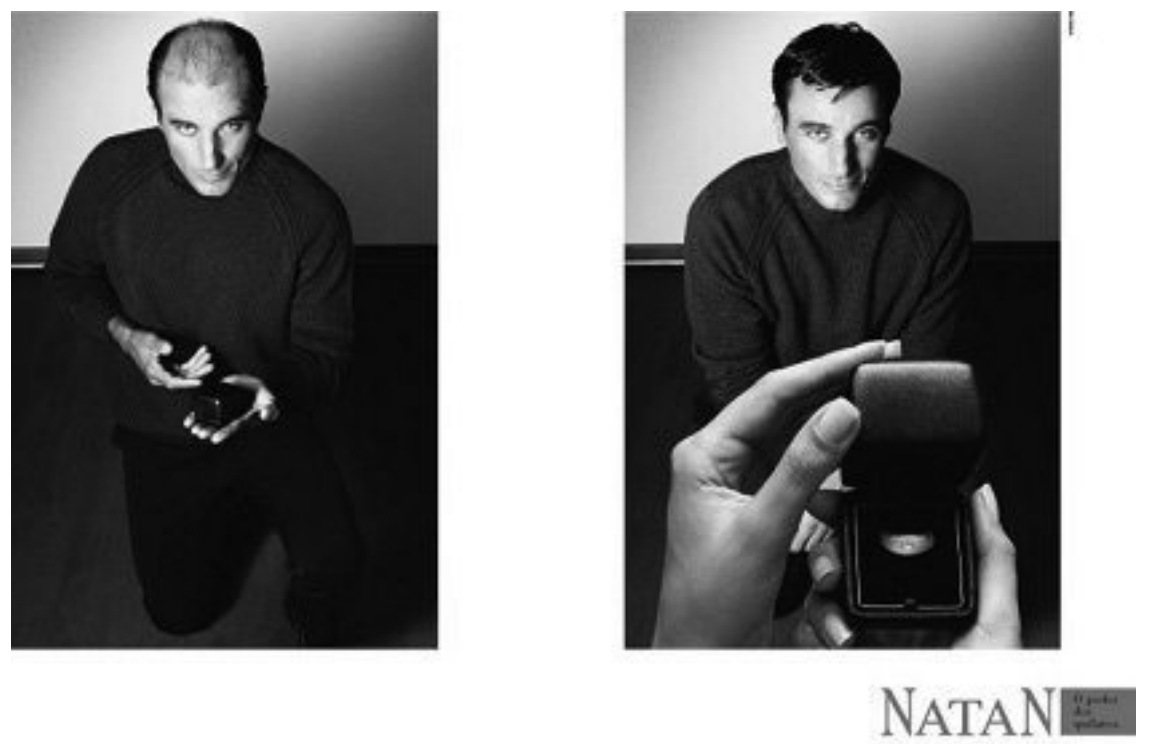

Peça 3

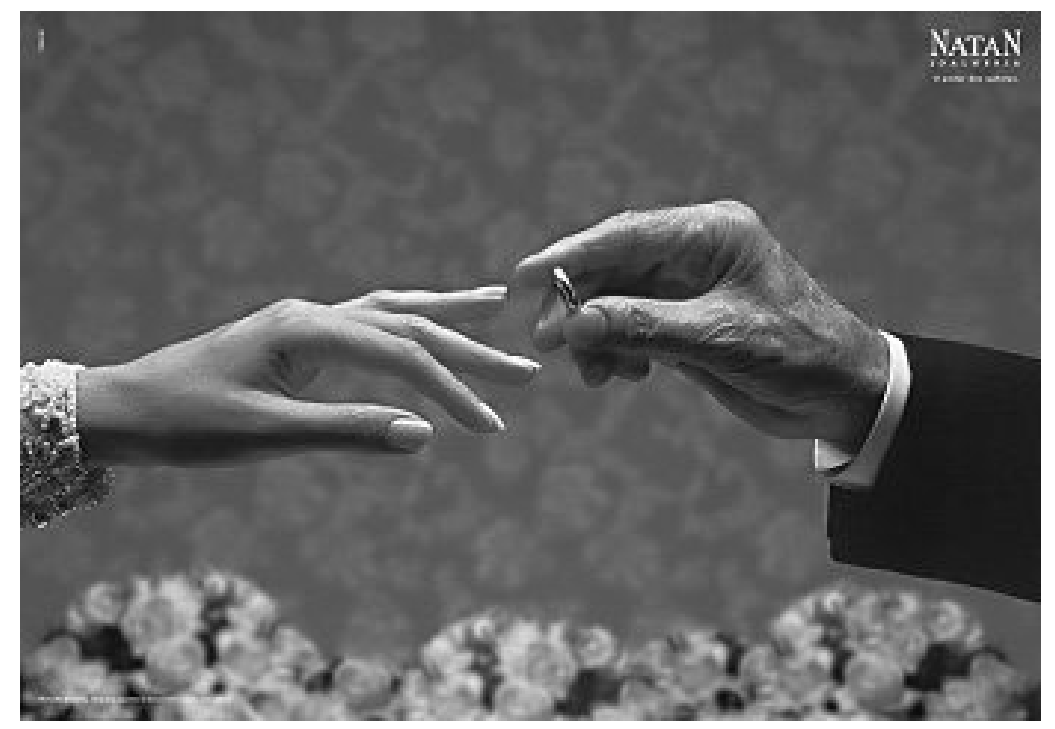

Peça 4 


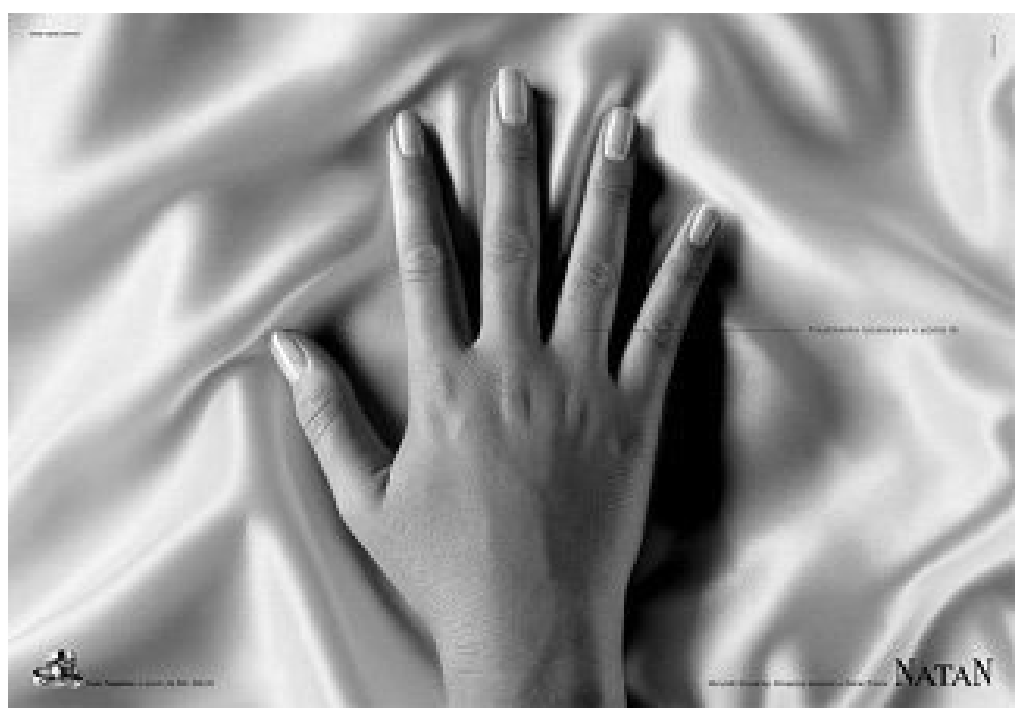

Peça 5

Em primeirolugar, deve-se salientar que, com muita frequência, o contato de interlocutores com o corpus é marcado pela aparição de sentidos ligados ao cômico, à graça e ao riso. São peças publicitárias interpretadas como sendo engraçadas. Trata-se de um efeito de sentido bastante recorrente.

Essa interpretação, que pode soar como óbvia, natural e única, é, antes de tudo, resultado do assujeitamento ideológico que provoca no indivíduo a ilusão de evidência de sentidos. Contudo, a atenção cuidadosa aos detalhes das peças pode fazer surgir uma importante questão: Por que são engraçadas? O quê nestes anúncios é capaz de provocar o riso? Com certeza, nenhum dos significantes constituintes destas práticas discursivas carrega, originalmente grudado a si, o "gene" do humor, mas, da forma como são apresentados, têm a capacidade de fazer surgir este efeito.

Em primeiro lugar, deve-se destacar a presença do mecanismo de deslocamento. Como apontado por Freud (1969), este mecanismo tão característico do processamento onírico está presente também na gênese do chiste, assim como a condensação e a representação. Nos sonhos, através do deslocamento, "as coisas que estão situadas na periferia dos pensamentos oníricos, e que são de importância menor, passam a ocupar uma posição central, aparecendo com grande intensidade sensória no sonho manifesto, 
e vice-versa" (1969: 188). O valor atribuído, através do "empréstimo" de catexia, a coisas desimportantes, então, provoca no pensamento consciente a impressão de raciocínio falho, de erro, percebido através de uma sensação de estranhamento, de surpresa. Acredita-se que repousa justamente aí, na surpresa causada pela discrepância entre a coisa esperada e a deslocada, um dos fatores comicizantes das peças.

Em termos discursivos, pode-se dizer que há um processo metafórico, já que um significante é sobreposto a outro, passando a carregar também os sentidos anteriormente atribuídos ao segundo. Dito de outra forma, um significante assume os sentidos de outro. No caso do sonho, há um apagamento/esquecimento consciente do significante original, coisa que não acontece, necessariamente, no chiste. Neste, o deslocamento é feito através de uma suspensão contextual, ou seja, recorta-se certo significante de seu contexto habitual e se o aplica a outro, bastante distinto, gerando a novidade e a graça. A peça de número 5 fornece um bom exemplo de deslocamento, já que os sentidos comuns atribuídos ao ponto G, geralmente ligados à região vaginal, são trazidos a outra parte do corpo da mulher, a mão. Como efeito do deslocamento, poder-se-ia esperar que surgissem questionamentos acerca da veracidade da informação, supondo um equívoco por parte do enunciador. É claro que, na grande maioria das vezes, esse questionamento não aparece porque se percebe a intenção chistosa do anúncio. Nos anúncios 1, 2 e 3, também parece haver um deslocamento, já que o anel assume o lugar de algo capaz de emagrecer e embelezar, assim como os produtos de beleza ou dietas comumente oferecidos em canais de compras. Nestes canais, frequentemente é usada a fórmula "antes e depois" para atestar a eficiência do produto. São mostradas fotos dos clientes antes e depois de usarem o produto, justamente como nos anúncios em questão.

$\mathrm{O}$ anúncio 4, contudo, não parece conter nenhum deslocamento cômico real. O mesmo efeito do deslocamento parece ser obtido pela incompatibilidade entre as aparentes idades das mãos envolvidas nas fotos - e as consequentes idades de seus donos. Revela-se aí uma formação discursiva dominante que considera normal e esperado que velhos se casem com velhas e jovens com jovens. A filiação a esta formação discursiva pode ser considerada essencial para a efetividade do anúncio 4.

Contudo, a simples presença de deslocamento não é suficiente para garantir o teor cômico dos anúncios. Parece notório que nem todo deslocamento é capaz de suscitar este efeito. O deslocamento passa a ser considerado, então, apenas uma importante condição de produção. 
É importante salientar que estes anúncios parecem apresentar um funcionamento próximo ao dos chistes, ou seja, provocar, devido a um consentimento inconsciente do interlocutor, prazer através do cômico. É justamente neste consentimento que parece residir a principal chave para se pensar os efeitos provocados pelo corpus. Não custa relembrar o caráter liberador presente nos chistes, o qual, segundo Freud (1969), só é possível graças a uma identificação do espectador com os sentidos veiculados por eles. Os chistes encontram eco nestes interlocutores e, por isso, são bem sucedidos.

No caso dos anúncios, acontece o mesmo. Através da flexibilização de algumas interdições, devido ao tom cômico das peças, alguns sentidos, referentes, por exemplo, à significação da mulher como interesseira, são autorizados. Todavia, é importante lembrar que estes sentidos são autorizados porque são possíveis, porque há um eco. Dito de forma mais simples, são sentidos que estavam lá anteriormente, porém, censurados. Pode-se dizer também que não se trata de uma censura tão rígida, dado que o sentido se faz possível através do chiste. Resumindo, as peças, funcionando como chistes, parecem possibilitar um caminho de escape para certos sentidos/crenças inconscientes, através da flexibilização dos limites discursivos.

Portanto, parece razoável supor que a existência deste sentido sufocado, ou essa "verdade a se calar" (CASTEL, 1996), seja considerada outra importante condição de produção do discurso, sendo uma das responsáveis por esta direção assumida pelo movimento interpretativo.

Com tudo isso, no entanto, ainda não se encerra a questão acerca dos fatores que levam estas peças a serem interpretadas como cômicas. Não há nada inerente a elas que garanta que a interpretação não vá, por exemplo, para o lado da ficção científica. Não há nada que garanta que a pessoa ria em vez de sentir raiva, ou o que seja. Não há escritos que digam "isso é uma peça cômica, portanto ria".

Nos anúncios 1, 2 e 3 do corpus, que são aqueles onde há uma imagem anterior e uma posterior à revelação da joia, pode-se notar algo em comum entre os homens de antes da joia, a saber: todos eles possuem traços físicos bastante distintos daqueles que são considerados os traços da beleza padrão vigentes. Um deles é "gordinho", outro é descaradamente careca e outro é estrábico e com o nariz muito grande. Acrescenta-se o fato de que o careca e o estrábico estão sorrindo, mesmo que levemente. 
Percebe-se, então, que eles se encaixam perfeitamente na descrição de tipos publicitários: há "uma pessoa com nariz grande" e "vesga", há uma pessoa "gorda", todas "não-bonitas dentro do conceito publicitário"; só não há uma referência direta à calvície, porém, ela se encaixa na não-beleza publicitária.

Esse banco de imagens, bastante semelhante a um dicionário, fornece um bom panorama sobre parte do interdiscurso publicitário, tangente ao cômico. Mostra de que maneira estas imagens, referentes aos aspectos físicos dos atores, vêm sendo significadas ao longo da História. O total destas significações forma o interdiscurso. Qualquer interlocutor que entre em contato com estes anúncios, de alguma forma, recorre ao interdiscurso para interpretá-los. O que, contudo, há de fato de engraçado em uma pessoa estrábica, ou acima do peso? Nada. Trata-se de uma construção destes sentidos, ideológica e historicamente determinada.

Em uma sociedade como a nossa, onde os padrões são tão bem impostos e aceitos por grande parte da população, parece razoável supor que estar acima do peso ou ficar careca seja significado como uma grande ameaça, talvez tão perigosa quanto a loucura para alguns. Supõe-se, então, que formas de estigmatização são criadas, a fim de afastar este perigo, o perigo de estar fora do padrão de beleza, como está um "gordinho". Todavia, existem interditos, o discurso está sujeito a uma política, e o "politicamente correto" não permite que sejam criadas barreiras tão nítidas, através da estigmatização publica de um "gordinho", por exemplo. Para tanto, deslocase, como já discutido, para os chistes ou os tipos, das peças publicitárias. Como aponta Orlandi (1999), a interpretação está sujeita à ideologia. Em nossa sociedade, parecem ainda estar bastante presentes, apesar de disfarçadas, formações discursivas em que a exclusão do "diferente" se atualiza.

Voltando, após esta digressão, às condições de produção, supõe-se, então, que a presença de tipos historicamente marcados como engraçados funciona como uma espécie de sinal indicativo de que a prática deve ser interpretada segundo o prisma do cômico, que é reforçado pelo deslocamento. A presença do cômico, então, autoriza a aparição de sentidos ocultos censurados. Dito de outra forma: nestas peças, a presença de tipos publicitários parece, de certa forma mais ou menos eficiente, direcionar o olhar para o cômico, permitindo a aparição de sentidos inconscientes "politicamente incorretos". O deslocamento estaria encarregado da estética da peça, responsável pelo estranhamento e surpresa. 
Após esta breve reflexão, pode-se supor, com alguma segurança, que há uma tentativa, por parte dos elaboradores das peças, de construir anúncios engraçados, que atinjam o interlocutor de forma a suscitar o prazer cômico. Imersos como estão no universo publicitário, é bastante provável que tenham escolhido a dedo os "tipos" mais eficientes neste sentido. Esta hipótese parece reforçada pelo fato de que, nas peças 2 e 3 , houve uma distorção da pessoa real a fim de transformá-la em um "tipo". Acredita-se que a pessoa do tempo posterior à aparição da joia seja o modelo real, ao passo que a pessoa anterior à joia parece ser resultado de algumas alterações de fisionomia, feitas em computador.

Os produtores dos anúncios demonstram, então, estando imersos em formações discursivas dominantes no mercado publicitário, que fazem uma escolha deliberada pelo uso do cômico, o que não significa dizer, contudo, que são senhores de suas escolhas, que por sua vez são ideologicamente determinadas, porém, se apresentam sob a roupagem da autonomia do sujeito. A escolha mais importante feita pelos criadores da peça, contudo, diz respeito ao uso da linguagem não-verbal. E torna-se essencial que se questionem os possíveis motivos desta escolha.

Seriam os sentidos produzidos pelas peças tão específicos que não poderiam ser veiculados de outra maneira, através de outras linguagens? Seriam tão difíceis de produzir quanto a combinação de notas em um acorde dissonante? Sabe-se que os sentidos específicos produzidos pelo corpus, da maneira como foi feito, jamais seriam alcançados através de outras linguagens, contudo, acredita-se que a escolha do não-verbal não se deva a isso, até porque, como será visto, trata-se de um corpus muito mais verbal do que parece.

A presença de um slogan - "o poder dos quilates" - em todas as peças, menos em uma, parece colocar as imagens como ilustração do que é apresentado verbalmente. Trata-se de um uso bastante comum das linguagens não-verbais, como aponta Souza (1997). O slogan parece se apresentar como um título da obra, porém, possui uma função bastante explicativa e não apenas de nomeação. Sem maiores aprofundamentos, é como se dissesse "veja, é isso que os quilates fazem". A imagem perde sua autonomia e passa a ser interpretada segundo a explicação verbal, porém, não deixa de fazer parte do todo da prática discursiva; no entanto, o nãoverbal parece ser a linguagem predominante. O slogan parece apenas estar a serviço de uma espécie de garantia de que o "recado" seja dado, para que a publicidade seja eficiente e venda o produto. 
Já na peça 5, o caráter explicativo do verbal é elevado ao extremo, já que sem o enunciado não há nada que ligue a mão de mulher estendida às joias. É a frase "finalmente localizado o ponto G" que dá sentido à foto. Sem essa frase, a deriva seria incontrolável. Nesta peça, ao contrário de todas as outras, parece haver predomínio do verbal. Contudo, os enunciados sempre aparecem em tamanho bastante reduzido quando em comparação às imagens. Isso parece demonstrar que se teve a intenção de privilegiar o não-verbal em todos os casos, porém, era necessário que se "garantisse" o sentido desejado através do verbal. Por que, então, privilegiar o não-verbal se ele é considerado justamente uma ameaça à intenção interpretativa dos criadores e se ele parece estar submetido à "explicação" verbal?

Acredita-se que o sentido geral desejado pelos produtores, a saber, a ideia de que esta joia - que está associada ao dinheiro, poder etc. - é capaz de produzir esta transformação de tornar os homens mais atraentes etc., poderia ser conseguido, aproximadamente, através da linguagem verbal somente, não necessitando de significação através de imagens. Esse fato indica que esta escolha atende a um propósito.

Levanta-se, então, a hipótese de que a escolha de "tipos", na tentativa de direcionar a interpretação para o humor, e a escolha da linguagem não-verbal devam-se a uma tentativa de não implicação com o dizer, com a prática discursiva. Se a peça soar ofensiva, não há problema, pois é apenas um chiste, uma brincadeira. Se ofender de alguma forma a mulher, pode-se afirmar que, por se tratar de uma linguagem não-verbal, esta interpretação é do interlocutor, não tendo os criadores responsabilidade por esta ofensa. Trata-se de maneiras de significar estas duas linguagens que refletem diretamente em como elas são usadas na mídia ou na vida cotidiana. Os criadores deste material podem simplesmente dizer "nós não dissemos nada", o que é um dos efeitos da forma como o falante cotidiano se relaciona com as linguagens: o que diz, o que comunica, só pode ser verbal (ORLANDI, 1995).

O uso das imagens, então, parece ter servido à diminuição do choque e da rejeição causados pelo dizer polêmico, já que conseguiu direcionar a interpretação ao cômico através dos tipos publicitários, e lançar sobre o interlocutor a responsabilidade da interpretação. Caso os criadores da peça tentassem fazê-la através da linguagem verbal, estariam provavelmente sujeitos a uma censura social violenta, pois se tem a impressão de que o verbal é mais transparente, o que supostamente responsabiliza mais o enunciador, já que o ouvinte pode pensar "você disse isso e ponto", supondo 
a não interferência da interpretação. É provável que frases como "O ponto $G$ fica dentro da carteira, mais precisamente entre os cartões de créditos" e "Só existe um ponto $G$ nas mulheres: é o que está na palavra ShoppinG" (genéricos verbais da peça 5 encontrados em sites de relacionamento da internet) não fossem bem aceitas, por exemplo.

Em todas as peças do corpus, a presença da joia, do anel, está associada ao sucesso com o sexo feminino: o homem passa a ser visto como mais bonito - e bastante bonito -, um homem mais velho consegue conquistar uma jovem e uma mulher consegue, finalmente, encontrar o prazer sexual do tão falado ponto G. A joia assume, então, o caráter de adorno sexual, tanto no que diz respeito à conquista do sexo oposto quanto ao desempenho sexual. Há claramente um apelo à sexualidade e, por que não dizer, ao erótico.

No caso das três primeiras peças, a abertura da caixa e consequente revelação da joia atuam como uma espécie de ritual de passagem, através do qual se muda o olhar de quem observa aquele que presenteia. Acontece uma mudança drástica na forma como esta mulher interpreta o homem a sua frente. Há uma mudança de interpretação devido ao acréscimo de uma importante condição de produção: a presença da joia. O homem de fato não mudou, mas mudou a maneira como ele é significado pela mulher que recebe $o$ anel.

Tomemos a peça número 1 como exemplo a fim de aprofundar um pouco a análise: neste anúncio, se vê, no tempo anterior à joia, a imagem de um homem com uma caixa de joia fechada nas mãos. $\mathrm{O}$ enfoque não permite que se veja seu rosto, apenas o tronco, os braços e as pernas até a altura da metade do fêmur, mais ou menos. Este homem está usando apenas uma toalha azul, como se acabasse de sair do banho, ou seja, seu tronco está descoberto, mostrando que ele se encontra, por assim dizer, um pouco acima do peso. Muito pouco se pode ver do fundo da imagem. No segundo momento, quando aparecem as duas mãos de uma mulher segurando a caixa aberta e se pode ver o anel, o homem já não é mais "gordinho"; é forte: tem os músculos definidos etc., conforme os padrões vigentes de beleza na mídia. A posição que ocupa é muito similar à do homem do primeiro momento e pouco se pode ver do fundo.

$\mathrm{O}$ fato de o homem estar usando uma toalha tem muita importância para a interpretação deste anúncio. Se ele tem a liberdade de usar apenas toalhas na frente da mulher, é bastante provável que eles já se conheçam há algum tempo e que tenham uma relativa intimidade. É provável também que já tenham feito sexo um com o outro. Pois bem, como dito acima, há 
uma mudança importante na maneira como o mesmo corpo é interpretado. A palavra corpo foi escolhida propositalmente, pois é isso que aparece: um corpo de homem, sem cabeça. $O$ corpo que aparece antes da joia se encaixa no padrão dos já discutidos "tipos", e em sua relação com o interdiscurso está longe de ser interpretado como uma fonte de interesse sexual. Muito pelo contrário, os usos destes "tipos" estão relacionados ao cômico, ao deboche, àquilo de que se deve rir e não àquilo pelo que se deve ter interesse. Não são os "tipos" gordinhos que saem nas capas das revistas e nas novelas com o corpo descoberto etc. A imagem de um "tipo" gordinho não está associada ao atraente, está mais relacionada ao estigma da obesidade ou ao perigo do colesterol, por exemplo. Por outro lado, o corpo que aparece após a joia é um exemplo de ideal de beleza veiculado na mídia, é tido como meta de corpo bonito a se alcançar devido aos usos de sua imagem ao longo do tempo. É notório que, no que tange ao ideal publicitário, uma barriga de "tanquinho" é muito "sexy" e deixa as mulheres muito interessadas, ao passo que uma barriga flácida, como a do primeiro corpo, é tida como desestimulante sexualmente.

Portanto, um dos sentidos importantes que este anúncio pode produzir em um homem que se identifique como o "tipo" gordo se aproxima de uma espécie de promessa de que, dando um anel à mulher, algo vai mudar severamente. Não que este interlocutor acredite que de alguma forma seu corpo vai realmente mudar, mas a esperança de que a mulher passe a se interessar por ele assim como supostamente se interessaria pelo corpo musculoso é, mesmo que inconscientemente, despertada. $\mathrm{O}$ anúncio pode veicular a promessa de que, com o anel, o homem se tornará mais interessante, passará a ser "visto com outros olhos". Deve-se salientar que a identificação do consumidor com o "gordinho" parece se dar de forma indireta, inconsciente, já que inicialmente o consumidor faz o papel do terceiro na fórmula do chiste, aquele para quem é contado algo de alguém, no caso o "gordinho". Além disso, parece importante que o consumidor não se sinta ofendido com os anúncios para que eles funcionem.

Inúmeros são os programas de TV, colunas de revista etc. que se propõem a salvar os pobres mortais desta desgraça, ensinando-lhes como fazer sexo e obter prazer. É neste contexto que a peça número 5, por exemplo, extrai sua força e seu impacto sobre os interlocutores. Todos necessitam saber onde fica o ponto $\mathrm{G}$ e como fazer isso e aquilo para, finalmente, se livrarem deste mal terrível que acomete nosso sexo.

No anúncio número 1, então, podem ser vistos dois momentos muito 
distintos separados pelo "poder dos quilates". Os quilates têm o poder de transformar a maneira como o casal em questão se relaciona sexualmente, passando da situação cotidiana normal, mole e degradada, como aponta Foucault (2003), para uma situação ideal, quase paradisíaca, em que o homem exibe toda sua masculinidade e potência a uma mulher muito interessada e receptiva, característica que parece insinuada pela caixa de joias aberta em suas mãos, mais bem discutida a seguir. Os quilates, então, parecem ter o poder de cura desta miséria sexual que supostamente nos acomete e que, como nos ensinam os sexólogos da TV, devemos combater a todo custo. Têm, então, um potente poder afrodisíaco, quase milagroso.

$\mathrm{O}$ anúncio número 5 é bom exemplo desta promessa de cura da "doença do sexo". Está implícito que com um anel o famoso ponto G, "o santo gral (sic) do orgasmo feminino", como é definido em sites de relacionamento, será estimulado, propiciando imenso prazer.

O fato de, no anúncio 1, o pênis do homem ser metonimicamente substituído pela joia, pelo anel, parece reforçar esta hipótese, já que a joia pode substituir um pênis talvez não tão interessante, fazendo com que a mulher volte sua atenção para este órgão do homem. Esta substituição parece deixar bem claro o caráter de adorno sexual que assume a joia neste anúncio. Não se trata simplesmente de estética, trata-se de uma melhora na habilidade sexual. É importante ressaltar também a posição fálica que assume o anel. Parece uma boa analogia de como sexo e poder são considerados próximos na sociedade contemporânea. Aliás, através desta substituição do anel pelo pênis, os criadores do anúncio parecem fornecer uma boa pista de suas filiações ideológicas e dos sentidos que atribuem à relação entre homem e mulher.

\section{CONSIDERAÇÕES FINAIS}

Vale lembrar que qualquer corpus é passível de inúmeras formas de análise e que cada pesquisador constrói seu recorte e seu dispositivo analítico. Logo, não se espera haver esgotado um corpus tão rico como esse. Crê-se, contudo, que alguns importantes aspectos referentes aos usos do não-verbal tenham sido expostos.

Para finalizar, a fim de atestar a importância da especificidade da matéria significante sobre o sentido produzido, propõe-se uma espécie de truque. A proposta é que o leitor observe atentamente a peça número 1, atentando para os dois corpos presentes. Após alguns momentos desta observação, propõe-se, então, tentar substituir a figura do "tipo" gordo pelo gordo que 
se encontra na peça 6 , como se, no anúncio, fosse utilizada a figura do segundo gordo em vez da figura habitual.

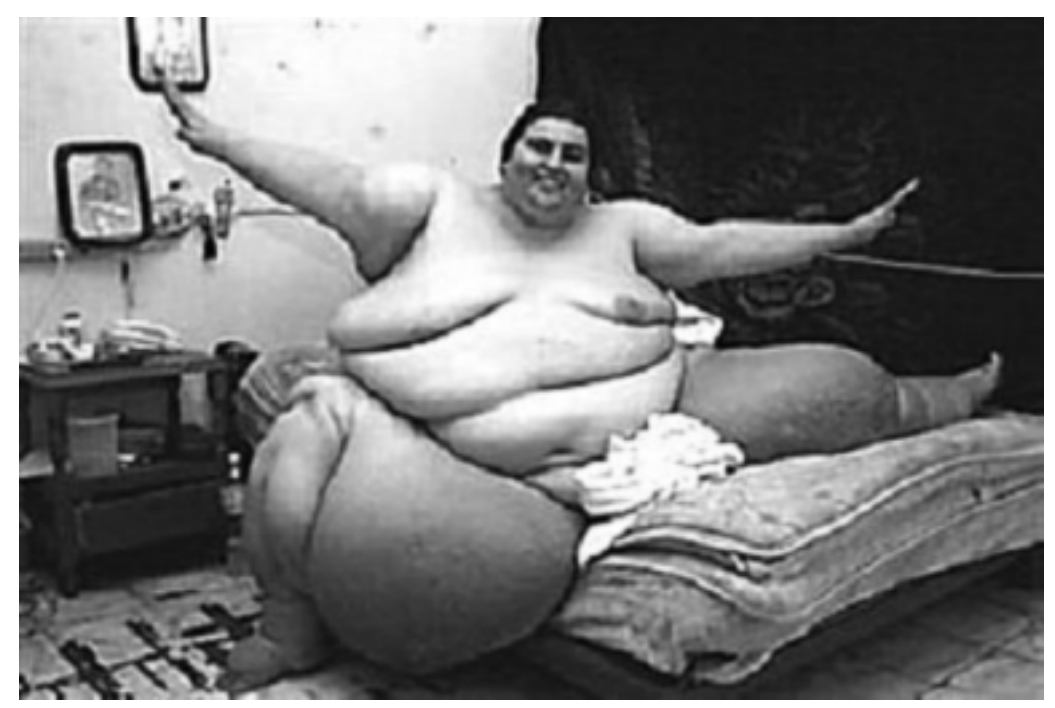

Peça 6

Após a tentativa, é bastante provável que se perceba a diferença entre os sentidos provocados. Trata-se da vivência da diferença que a especificidade da linguagem provoca. A experiência mostra também um importante limite da linguagem verbal. Se se tivesse que descrever verbalmente, jamais se alcançariam estes sentidos. Verbalmente falando, os dois gordos são quase a mesma coisa. Por mais que se tente diferenciá-los, apurando a descrição, serão sempre dois gordos, o que destrói a enorme distância entre eles. Não se pode descrever as dobras das pernas ou o sorriso. Estas coisas o verbal não alcança.

\section{REFERÊNCIAS BIBLIOGRÁFICAS}

AGUIAR, V. T. O verbal e o não-verbal. São Paulo: EdUnesp, 2004.

CASTEL, P. H. Cômico. In: CASTEL, P. H. Dicionário enciclopédico de Psicanálise: o legado de Freud e Lacan. Trad. V. Ribeiro \& M. L. X. A. Borges. Rio de Janeiro: Jorge Zahar, 1996. p. 55. 
FOUCAULT, M. História da sexualidade. Trad. M. T. C. Albuquerque \& J. A. G. Albuquerque. Rio de Janeiro: Graal, 2003. v. 1: A vontade de saber.

FREUD, S. Os chistes e sua relação com o inconsciente [1905]. In: FREUD, S. Obras psicológicas completas de Sigmund Freud. Trad. M. Salomão. Rio de Janeiro: Imago, 1969. v. 8.

MAINGUENEAU, D. Genèses du discours. Bruxelles-Liège: P. Mardaga, 1984.

ORLANDI, E. P. Análise do Discurso: princípios e procedimentos. Campinas: Pontes, 1999.

ORLANDI, E. P. Efeitos do verbal sobre o não-verbal. Rua: Revista do Núcleo de Desenvolvimento da Criatividade, v. 1, p. 32-44, 1995.

PANTONI, R. V. Letramento e ideologia: relação entre práticas letradas e o processo de construção da subjetividade. Dissertação (Mestrado em Ciências) - Faculdade de Filosofia, Ciências e Letras de Ribeirão Preto, Universidade de São Paulo, 2002.

PÊCHEUX, M. O discurso: estrutura ou acontecimento? Campinas: Pontes, 1990.

PÊCHEUX, M. Papel da memória. In: ACHARD, P. (Org.). Papel da memória. Trad. José Horta Nunes. Campinas: Pontes, 1999. p.15-25.

PÊCHEUX, M. Semântica e discurso: uma crítica à afirmação do óbvio. Campinas: Editora da Unicamp, 1988.

SOUZA, T. C. C. Discurso e imagem: perspectivas de análise do nãoverbal. In: SEGUNDO COLÓQUIO LATINO-AMERICANO DE ANALISTAS DEL DISCURSO. La Plata; Buenos Aires, Argentina, 1997. (Comunicação).

TFOUNI, L. V. O discurso na instituição hospitalar. In: SIMPÓSIO BRASILEIRO DE COMUNICAÇÃO EM ENFERMAGEM, 1., Ribeirão Preto, 1988. Anais... Ribeirão Preto: USP/EERP, 1988. p. 502-512.

TFOUNI, L. V.; LAUREANO, M. M. M. Que queres? O sujeito do discurso e seu desejo - o papel da ideologia. Consciência, v. 2, n. 18, p. 9-26, 2004. 